\title{
Resenha
}

\section{O TRABALHO COM A CRIANÇA-SUJEITO: NO AVESSO DO ESPECIALISTA}

\author{
Karla Patrícia Holanda Martins
}

\begin{abstract}
A
psicanálise, construída na universidade, partilha um novo testemunho da sua capacidade de colocar em cena a criança-sujeito, a criança-enigma que põe em desenho os ciframentos do desejo, os discursos da cultura e as formas de laço social. O olhar que orienta o psicanalista se faz de revés, pelo avesso das linhas que tramam o discurso do especialista, fazendo ali surgir figurações outras capazes de balizar as coordenadas éticas e metodológicas no trabalho com crianças na atualidade.

O avanço das neurociências e o recrudecimento do naturalismo científico colocam a psicanálise em um cenário de certa forma já visitado por Freud e nos convoca a resistir aos imperativos sociais que se organizam na contramão das condições de estruturação do sujeito; nesse cenário, analistas em trabalho na universidade, na clínica e na escola, marcados pelo impossível de um dizer todo, são reconduzidos à direção de colocar o possível a trabalhar.

Da pediatria à clínica psicanalítica, passando ainda pela formação de professores, os desafios e impasses encontrados são amplamente discutidos no conjunto de artigos da coletânea $A$ psicanálise e o trabalho com a criança-sujeito: no avesso do especialista, organizado pelas psicanalistas e pesquisadoras Sandra Francesca Conte de Almeida e Maria Cristina Kupfer. A coletânea é fruto das investigações do Grupo de Trabalho "Psicanálise, Infância e Educação", da Associação Nacional de Pesqui-
\end{abstract}

Psicanalista, Professora do Departamento de Psicologia da Universidade Federal do Ceará, Professora-colaboradora do Programa de Pós-Graduação em Psicologia da Universidade de Fortaleza. 


\section{Resenha}

sa e Pós-Graduação em Psicologia ANPEPP. Tais investigações, atravessadas pela perspectiva ética da psicanálise, elaboram o ponto de esquize que diferencia o ver e o olhar. No avesso do especialista, o avesso da psicanálise se constitui por uma superfície que não se dá a ver senão em seus efeitos discursivos. Para fazer frente às distintas encenações do discurso do mestre é necessário colocar em jogo o discurso da histérica na sua interpelação política ao que se apresenta sem furos. Mais uma vez na história dos saberes psicanalíticos, é a interrogação que delimitará estratégias capazes de interpelar o mestre a produzir um saber inédito. As perguntas contidas nesta obra abrem novas linhas de pesquisa sobre o infantil e as figurações do Outro na clínica e na cultura, mas, principalmente, reafirmam a atualidade da psicanálise.

No texto "Dispositivos clínicos de orientação psicanalítica na formação de professores: entre o cuidado, o ensino e a transmissão", Sandra Francesca discute princípios éticos que possam sustentar a posição do professor em trabalho na condição de "um sujeito em situação profissional", numa perspectiva de formação avessa ao desenvolvimento de competências e habilidades profissionais. $\mathrm{O}$ adoecimento psíquico do professor, como sintoma do mal-estar na educação, é aqui considerado em sua dimensão clínica, não com uma finalidade terapêutica, mas com vistas a fundar uma práxis onde cuidado, en- 
sino e transmissão sejam tomados como registros distintos que atravessam os dispositivos relativos ao ato de educar.

Seguem-se as reflexões de Bernard Pechberty no artigo "Entre o tratamento e a formação: conflitos identificatórios na relação pedagógica", onde o autor defende a importância de se considerar "a vida psíquica, consciente e inconsciente, atuante na relação pedagógica", em particular os processos identificatórios que, por vezes, comprometem a sustentação do lugar simbólico do professor, cabendo aos que acompanham a sua formação uma escuta sensível dos fenômenos transferenciais. Seguindo esta perspectiva, Cynthia Pereira de Medeiros e Suely Holanda ilustram, a partir do trabalho realizado no Núcleo de Educação Infantil - Pré-Escola de Aplicação da UFRN, "O trabalho subjetivo de uma professora às voltas com o impossível em jogo na demanda de uma menina que 'não acompanhava o grupo"'. A possibilidade de uma escuta orientada pela psicanálise pode colocar em cena a dimensão da angústia e os processos identificatórios que, por vezes, obstaculizam os processos educativos.

A partir dos resultados da pesquisa brasileira multicêntrica de indicadores clínicos de risco para o desenvolvimento infantil e do trabalho conduzido pela Associação PREAUT, na França, os psicanalistas Rogério Lerner, Graciela Cullère-Crespin e Maria Cristina Machado Kupfer discutem os efeitos na clínica pediátrica da formação para a detecção de sinais iniciais de risco para o desenvolvimento. Em ambas as propostas, o objetivo da formação era introduzir na semiologia pediátrica a consideração sobre os percalços no desenvolvimento infantil e suas operações subjetivantes fundamentais, permitindo-lhes conceber a clínica funcional do primeiro ano de vida articulada à dinâmica relacional do bebê. Os efeitos desta formação recaem ainda sobre as possibilidades de um encaminhamento ético-responsável da criança em risco e sobre as formas de organização e gestão dos serviços de saúde, solidários de uma inteligibilidade clínica, efetivamente, de uma clínica do sujeito.

No artigo " $\mathrm{Da}$ formação de educadores e de um ensino da Psicanálise na universidade" Leandro de Lajonquière nos lembra que, ao se transmitir a psicanálise aos educadores (mas não seria diferente em outros contextos), o que se ensina é "algo" da ordem da experiência e da invenção freudiana, "algo que escorrega ou se desloca na contabilidade do ensino, no balanço" (p. 102). E é desse algo chamado castração que aquele que professa tem que dar testemunho, ainda que disso o discurso tecnicista da Pedagogia nada queira saber. Foi no contexto de 


\section{Resenha}

uma reflexão sobre os destinos da castração, ao fim de uma análise, que Freud (1937/1980) implica o analisar nas três profissões impossíveis. E aqui, ao fim de sua vida, Freud inclui, na sua obra, a ferida da própria psicanálise.

Os limites e as possibilidades da aplicabilidade da psicanálise ao campo pedagógico, frente aos imperativos de completude do saber científico, são discutidos no artigo "Da Medicina à Psicanálise: considerações acerca das articulações da Educação Especial com a Clínica”. A experiência de Itard e sua condição de especialista são tomadas pelas autoras Maria Celina Peixoto Lima e Maira Sampaio como paradigmáticas de uma educação que, pela via da técnica e pelo ideal da cura, apaga a dimensão da singularidade e, portanto, do sujeito. Problematizando ainda se, na injunção dos saberes clínico e pedagógico (por exemplo, na prática psicopedagógica), perderíamos a especificidade de cada um desses campos, com risco de descaracterizar a proposta psicanalítica e pedagógica, perguntam: "O que implicaria pensar uma Psicopedagogia psicanaliticamente orientada?" (p. 123).

A questão igualmente implícita no artigo "A psicopedagogia do terceiro tempo e o avesso do especialista" é discutida por Odana Palhares chamando o problema ao campo da ética, em importante contraponto entre a educação ideal e o ideal de educação: "É no campo da ética que a psicopedagogia do terceiro tempo pode intervir na escuta da singulari- 
dade de um sujeito, cujo desdobramento possa ser acolher a inventividade" (p. 150).

Frente à instrumentalização do saber, o declínio do saber da experiência e suas consequências à transmissão são problematizados por Ana Maria Moraes Fontes que, inspirada pela perspectiva de Octave Mannoni (1969), retoma o trabalho da governanta Mme. Guérin com o jovem de l'Aveyron. Enquanto o programa reeducativo de Itard fracassava, Mme. Guérin se punha a brincar com o jovem. Se o Victor de Itard é o conto natalino da ciência positivista no ocaso do século XVIII, o Victor de Mme. Guérin e seu brincar antecipam em 100 anos a ciência dos sonhos freudiana, lembrando-nos que há transmissão quando são mantidas as condições de filiação e, portanto, de inscrição do sujeito na cultura.

Com vistas a ilustrar a significativa distância entre a oferta de práticas escolares e as demandas dos supostos aprendizes, Ângela Vorcaro e Viviane Veras apresentam, a partir do fragmento de um atendimento de uma garota, a discrepância entre o dito desinteresse em aprender e a chamada impotência dos professores na escola. Durante a avaliação de suas ditas competências cognitivas, a menina, em um feito de Emília, desloca, com seu truque, o especialista para a condição de aprendiz, colocando em ato a desarmonia e a heterogeneidade dessas diferentes posições. Afirmando que a relação de aprendizagem e a re- 


\section{Resenha}

lação sexual têm estruturas análogas, as autoras perguntam: "Como qualificar a estrutura que, na atualidade, tipifica esse laço no mercado de saber escolar?" (p. 174). A lógica narcísica, em jogo na contemporaneidade, incide sobre o impasse para manter o valor devido ao saber, já demarcado como relativo ao declínio da autoridade (Lebrun, 2004, 2008). Mas, na dialética da demanda e do desejo, ensinar e aprender por amor são tarefas fadadas ao fracasso, quando do amor se espera apenas a completude. A Pedagogia de hoje, ao atribuir "um caráter científico ao saber materno, fazendo dele o lugar da transmissão pedagógica" (p. 176), não consegue fazer vigorar um regime de trocas e mediação simbólicas capaz de ir ao encontro da ilusão narcísica e de complementariedade.

Em uma esteira semelhante, Rinaldo Voltolini, no texto "Poder, impotência e impossível no discurso pedagógico”, discute os pontos de contato entre a maternalização das propostas pedagógicas atuais e a sedução hipnótica, quando esta tira de cena a ordem da linguagem e a da autoridade do saber. Os três termos freudianos propostos em 1914 - recordar, repetir e elaborar - servem à indagação sobre os modos de exercício do poder na transferência e, em seu texto, aparecem simultaneamente como referências aos deslocamentos da função do amor nos processos do aprendiz (e do analisante). Enquanto na clínica freudiana da hipnose o termo da recordação era o fim último do trabalho de elaboração analítica, ao introduzir a elaboração (ducharbeiten), Freud (1914/1980) coloca em jogo no playground, a partir da repetição, o impossível na estrutura do saber; proposição esta com extensas consequências para os campos da educação e da clínica.

É também desse ponto de impossível na clínica psicanalítica que partem os textos "Tratando o impossível: transmissão e corpo e constituição do sujeito: o caso de uma adolescente autista" e "O menino da Big Ball”, respectivamente. No primeiro, Ana Beatriz Freire retoma a pesquisa clínica de sua equipe, a partir da intervenção junto a uma jovem autista. No avesso da presença invasiva do especialista, o tratamento do campo do Outro deve se orientar por uma ética que coloca em jogo o "deixar-se" descompletar do analista; no jogo do corta e cola, o corpo-significante se destaca do campo de gozo do Outro. Desse modo, supondo que o que está em jogo no tratamento da psicose não é uma ficção edipiana, mas uma ficção sobre o gozo, Suzana Faleiro Marroso, no texto O menino da Big Ball, discute outros recursos clínicos fora da norma fálica capazes de pro- 
duzir no tratamento analítico das psicoses uma espécie de "aparelhamento do gozo". Com o menino Big Ball a autora retoma, a partir de Lacan, os efeitos de alíngua sobre a transferência e suas consequências para a direção do trabalho analítico.

Em "Médicos educadores e professores terapeutas? Algumas relações entre o tratar e o educar" Maria Cristina Kupfer e Camille A. Gaviolli discutem a medicalização da educação. No cenário do declínio do poder do pater familiae, com a substituição de sua função educativa pela figura do médico, surgem verdades como efeitos de linguagem. Na contramão, fazem-se necessárias as propostas que objetivem resgatar ou propiciar a construção de um sujeito, onde as autoras incluem a Educação terapêutica, "ao educar, o educador terapeuta estará acompanhando a criança em seus tropeços e em seu enfretamento do Real" (p. 278). Concluem com um pedido ao médico e ao educador, respectivamente: que o primeiro deixe de educar e que o segundo possa tratar, o que não significará reproduzir o discurso das especialidades, mas cuidar da criança visando que esta encontre o seu estilo próprio de dizer sobre si mesmo.

A objetalização da criança é tema central dos dois artigos que finalizam a coletânea, "Um saber fazer com crianças e jovens" de Marcia Regina Lima Costa e Ruth Helena P. Cohen e "A criança-objeto" de Marcelo Ricardo Pereira. Partindo de um fa- 


\section{Resenha}

zer interdisciplinar no campo da clínica ampliada, as autoras discutem os efeitos de um dispositivo, por elas denominado "Brincante", para atendimento de crianças e jovens em tratamento oncológico. Da recreação à recriação, o sujeito-brincante reinventa, a partir da lógica do brincar, novas formas de subjetivar sua dor, reapropriando-se de sua condição de sujeito frente às inflexões das práticas e discursos médicos. Marcelo Pereira, evocando a dimensão da palavra na construção da obra da cultura, coloca em cena as relações entre a negação da palavra e o apagamento do sujeito, cujos efeitos se expressam, por exemplo, nas figurações da violência e no "empuxo" ( $p$. 311) ao gozo.

Assim, diante de temas tão atuais e que nos atravessam a partir dos mais distintos campos, fica esta sugestão de leitura para aqueles que, provocados pelo trabalho com a criança, sentemse igualmente convocados ao movimento hiperativo das pulsões, onde caberá ao homem almejar, na sua condição sempre infantil, o gosto pela repetição, pelos pedaços, pelos restos, já que neles reconhecem "o rosto que o mundo das coisas lhes mostra" (Benjamin, 1992, p. 46). O desejo articula o mundo das coisas ao mundo dos homens, eis o que também Freud nos ensina.

\section{REFERÊNCIAS}

Benjamin, W. (1992). Oficina. Rua de sentido único [1928] e Infância em Berlim por volta de 1900 [1932-38] (I. Sousa e C. Rodrigues, trads.). Lisboa: Relógio D'água.

Freud, S. (1980). Recordar, repetir e elaborar. In S. Freud, Edição standard brasileira das obras psicológicas completas de Sigmund Freud. (J. Salomão trad., Vol. 12, pp. 193203). Rio de Janeiro: Imago. (Trabalho original publicado em 1914)

Freud, S. (1980). Análise terminável e interminável. In S. Freud, Edição standard brasileira das obras psicológicas completas de Sigmund Freud. (J. Salomão trad., Vol. 23, pp. 239287). Rio de Janeiro: Imago. (Trabalho original publicado em 1937)

Mannoni, O. (1969). Chaves para o imaginário. Petrópolis, RJ: Vozes.

Melman, C. (2003). O homem sem gravidade: gozar a qualquer preço; entrevistas por Jean-Pierre Lebrun (S. Felgueiras, trad.). Rio de Janeiro: Companhia de Freud.

Lebrun, J. P. (2004). Um mundo sem limite: ensaio para uma clínica psicanalitica do social (S. Felgueiras, trad.). Rio de Janeiro: Companhia de Freud.

Lebrun, J. P. (2008). A perversão comum: viver juntos sem outro. (P. Abreu, trad.). Rio de Janeiro: Campo Matêmico.

kphm@uol.com.br 